\title{
Effectiveness and safety of Dabrafenib in the treatment of 20 Chinese children with BRAFV600E-mutated LCH
}

\author{
Ying Yang ${ }^{1}$, Dong Wang ${ }^{2}$, Lei Cui ${ }^{2}$, Honghao $\mathrm{Ma}^{2}, \mathrm{Na} \mathrm{Li}^{1}, \mathrm{Li}_{\text {Zhang}}{ }^{2}$, Hongyun Lian ${ }^{2}$, \\ Wei-jing $\mathrm{Li}^{1}$, Qing Zhang ${ }^{2}$, Xiaoxi Zhao ${ }^{2}$, Li-ping Zhang ${ }^{1}$, Yunze Zhao ${ }^{2}$, Tianyou Wang ${ }^{2}$, \\ Zhigang $\mathrm{Li}^{2}$, and rui zhang ${ }^{3}$ \\ ${ }^{1}$ Bejing Childrens Hospital \\ ${ }^{2}$ Beijing Children's Hospital \\ ${ }^{3}$ Beijing Children's Hospital
}

June 15,2020

\begin{abstract}
Background Langerhans cell histiocytosis $(\mathrm{LCH})$ is a rare disease with a high frequency of the BRAFV600E mutation. We sought to investigate the effectiveness and safety of Dabrafenib in children with BRAFV600E-mutated LCH. Procedure A retrospective analysis was performed on 20 children with BRAFV600E -mutated LCH, who were treated with Dabrafenib and followed up from November 1, 2016, to June 1, 2020. Results The median age at which the patients started taking Dabrafenib was 2.3 (0.6-6.5) years old. All patients were initially treated with chemotherapy and then changed to targeted therapy due to poor response or intolerance to chemotherapy. The overall objective response rate and disease control rate were $65 \%$ and $75 \%$, respectively. Among the 15 patients who had positive circulating cell-free BRAFV600E (cfBRAFV600E) mutation before Dabrafenib treatment, decreased cfBRAFV600E level was observed at the end of treatment $(\mathrm{P}=0.029)$. In 9 of 15 (60\%) patients, cfBRAFV600E level became negative within a median time of 3.0 months (1.0-9.0 months). All patients survived, and a half of them suffered a relapse or progression after Dabrafenib treatment. Grade 2 or 3 adverse effects occurred in 5 patients. Relief of adverse effects was obtained after symptomatic treatment, reduction of dosage or withdrawal. Conclusions Some children with BRAFV600E-mutated LCH may benifit from monotherapy of Dabrafenib, especially high-risk patients with concomitant HLH and intolerance to chemotherapy. The safety of Dabrafenib is notable. A prospective study with a larger sample size are required to determine the optimal dosage and duration of Dabrafenib.
\end{abstract}

\section{Hosted file}

Text file. Dabrafenib treatment in children with LCH.doc available at https://authorea.com/ users/333519/articles/459723-effectiveness-and-safety-of-dabrafenib-in-the-treatment-of20-chinese-children-with-brafv600e-mutated-lch

\section{Hosted file}

Table 1.doc available at https://authorea.com/users/333519/articles/459723-effectiveness-andsafety-of-dabrafenib-in-the-treatment-of-20-chinese-children-with-brafv600e-mutated-lch

\section{Hosted file}

Table 2.doc available at https://authorea.com/users/333519/articles/459723-effectiveness-andsafety-of-dabrafenib-in-the-treatment-of-20-chinese-children-with-brafv600e-mutated-lch

\section{Hosted file}


Table 3.doc available at https://authorea.com/users/333519/articles/459723-effectiveness-andsafety-of-dabrafenib-in-the-treatment-of-20-chinese-children-with-brafv600e-mutated-lch

\section{Hosted file}

Table 4.doc available at https://authorea.com/users/333519/articles/459723-effectiveness-andsafety-of-dabrafenib-in-the-treatment-of-20-chinese-children-with-brafv600e-mutated-lch
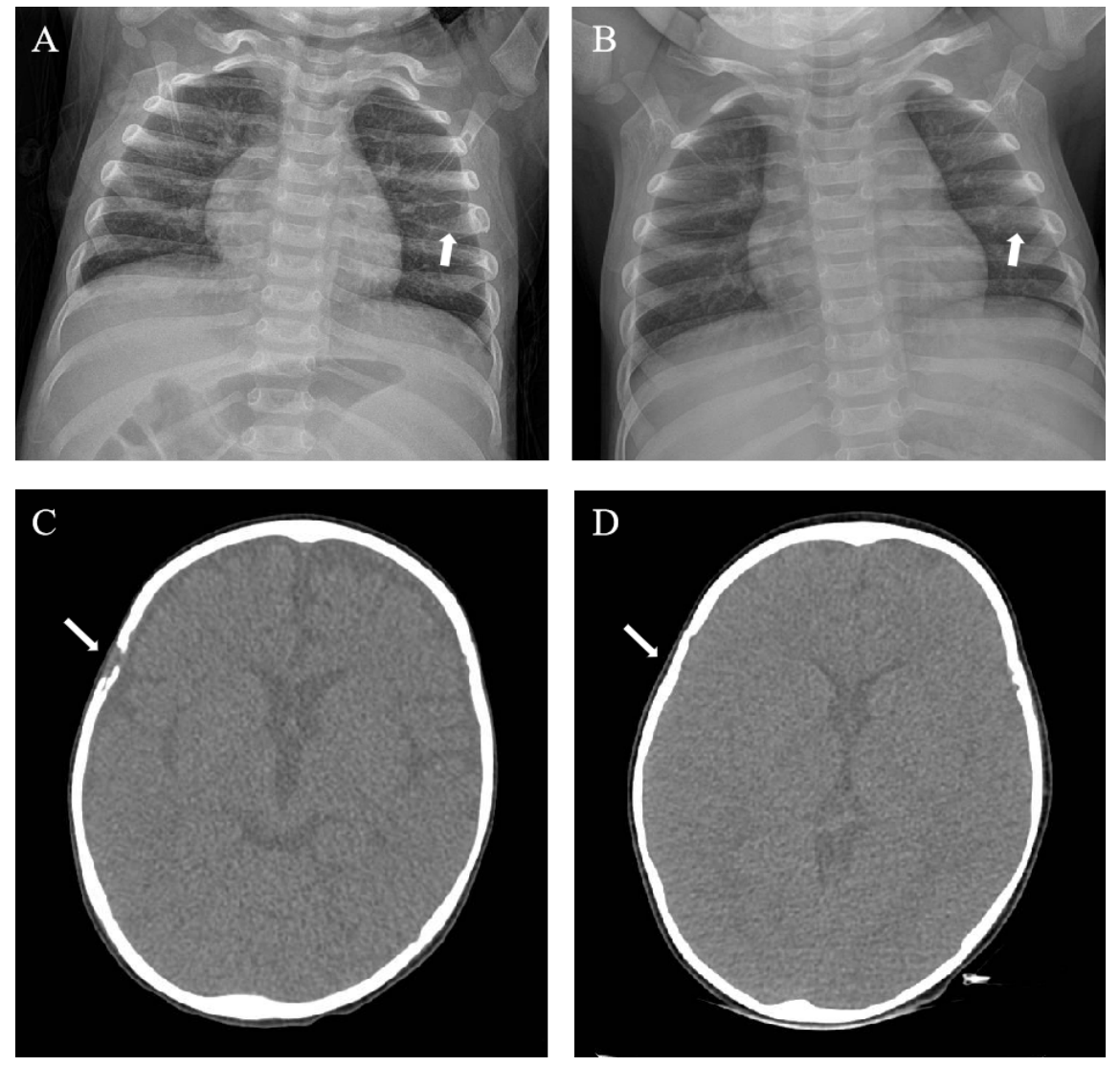

A

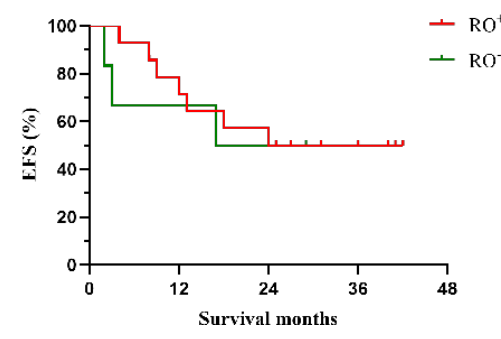

B

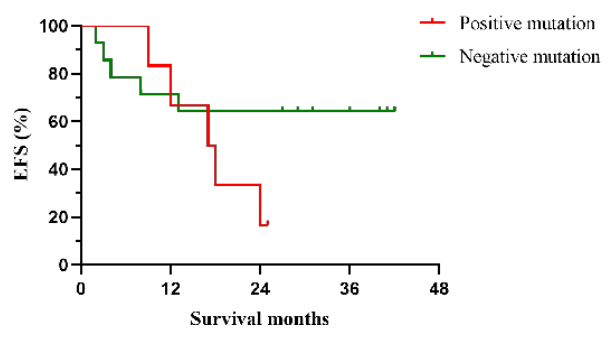

